\title{
A NARRATIVIDADE VISUAL EM DIÁLOGO COM O TEMPO: GOIANDIRA DO COUTO E AS INTERSECÇÕES COM O PASSADO COLONIAL NA CIDADE DE GOIÁS
}

\author{
Raquel Miranda Barbosa ${ }^{1}$
}

\section{Caminhos da Imagem}

Pertenço de fazer imagens. Opero por semelhanças. Manoel de Barros

O cruzamento entre história e imagens sob a ótica de sujeitos e tempos distintos, não é uma tarefa fácil. Para este estudo, propomos a comparação entre duas imagens anacrônicas quanto as temporalidades, porém, com peculiar semelhança formal. Tal "acaso" aguçou as inquietações epistemológicas que justificam esta narrativa histórica, balizada por dois discursos visuais, sendo, um oficial e o outro artístico sobre a Cidade de Goiás.

Cabe sublinhar que, assim como na escrita, o campo das visualidades permite diversas interpretações, pois o teor subjetivo da fonte visual impossibilita o esgotamento de sua leitura. Se de fato essa ação se tornasse uma realidade suprimir-nos-ia o sentido da inventividade do passado.

Tal operação envolve o discurso historiográfico assemelhando-se às metáforas e às utopias constitutivas e criativas de uma obra de arte. De tal modo, como estamos tratando de pintura e, ao mesclar as cores, o pintor vê materializado o seu desejo da forma, articularemos os conceitos de tempo, cultura e imaginário que imbricam-se no jogo relacional entre a história às imagens escolhidas para essa análise possibilitandonos “construir uma representação sobre o já representado" (Pesavento, 2005: 43).

Sob esse entrecruzamento, as análises desse estudo dar-se-ão pelo diálogo colacionado entre o prospecto português de 1751, documento que definiu o traçado urbano da capitania de Goiás. Em seguida, a obra Largo do Rosário, da artista plástica Goiandira do Couto $^{2}$, tela de 1976. Sugerimos então problematizações que norteiem "o

\footnotetext{
${ }^{1}$ Universidade Estadual de Goiás, Brasil.

2 “Goiandira do Couto é uma mulher que viveu há quase um século de história nessa cidade. Nascida no início do século XX, sob um berço cultural privilegiado, Goiandira do Couto chega à cidade de Goiás, ainda criança. Sob a égide de um sobrenome importante que integraria o rol das elites vilaboenses, a filha de Luís Ramos de Oliveira Couto e Maria Ayres do Couto recebe uma educação permeada de valores femininos tradicionais, acrescida de informações culturais voltadas para a arte e literatura, certamente
} 
uso documental da imagem "artística", como vetor para não só produzir História, mas também voltado para a elucidação de sua própria historicidade" (Menezes, 2003: 06). Ao apreciá-la como parte viva e integrante da realidade social, ressaltamos que o historiador, em sua narrativa, rompe silêncios retraçados pela interface entre as fontes iconográficos que sugerem as problematizações deste artigo.

Ressaltamos ainda, o tratamento analítico, em separado, que daremos a essas imagens. Dispô-las aqui justifica-se em nutrir as inquietudes que percorrem as páginas seguintes.

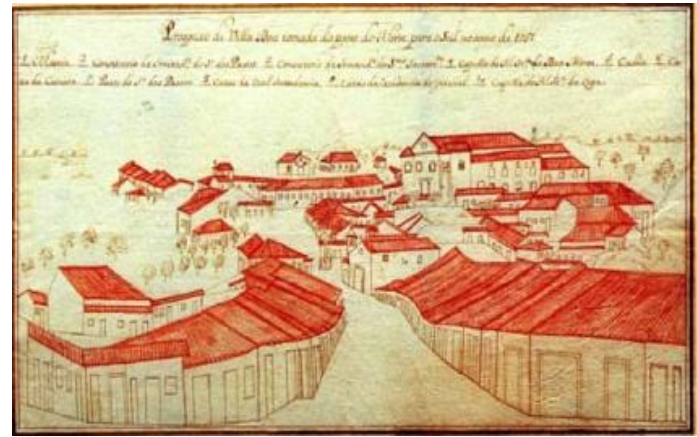

Figura 1: Prospecto de Vila Boa - Vista no sentido inverso, isto é, do norte para o sul, em 1751 (original da Casa da Ínsua, Portugal). IN: MORAES, Cristina de Cássia Pereira. "Do corpo místico de Cristo: irmandades e confrarias na capitania de Goiás (1736 a 1808)", 2012: 48.

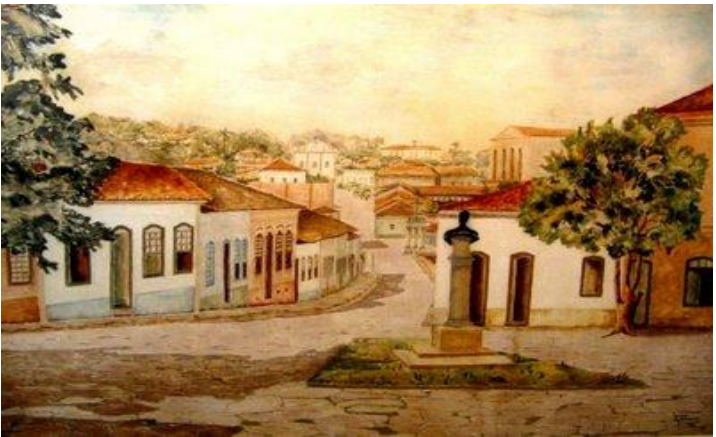

Figura 2: Goiandira do Couto, Largo do Rosário $(141 \times 93 \mathrm{~cm})$ - Vista da cidade, 1976. In: FERREIRA, Tais Helena Machado. "Faz uma casa com areia": a cidade de Goiás e as areias coloridas na trajetória de Goiandira Ayres do Couto. Dissertação (mestrado) UFRJ/EBA, Programa de Pós-Graduação em Artes Visuais, 2011: 179.

Introdutoriamente, por meio das fontes desse estudo, enxergamos a persistência do passado no presente. Os diálogos visuais que pretendemos estabelecer entre as duas imagens análogas para esta interlocução, ao nosso ver, desde um primeiro momento, sugerem-nos permanências das tradições oriundas de um passado colonial, vivido pela cidade de Goiás ${ }^{3}$, no século XVIII, após a descoberta do ouro nesses “sertões”.

transferidos pelo pai jornalista, desembargador e escritor, e, pela mãe, que se dedicava, deste aquela, época à pintura" (2011: 2). Cf. BARBOSA, Raquel Miranda. Muito além das telas douradas: narrativas pictóricas em Goiandira do Couto. Anais do XXVI Simpósio Nacional de História - ANPUH. São Paulo: jul.2011.

3 “Antiga capital do Estado de Goiás, surgiu com a chamada corrida do ouro. Foi fundada em 1727 por Bartolomeu Bueno da Silva Filho, com o nome de Arraial de Santana. Tornou-se Vila Boa de Goiás, em 1739, em homenagem a Bartolomeu Bueno e, ao mesmo tempo, aos índios Goyazes, seus primeiros habitantes. Na época, tomaram-se providências para a construção dos primeiros prédios públicos para criar condições de abrigar a administração local. Vila Boa de Goiás foi elevada a sede da capitania geral em 8 de novembro de 1749, quando se separou da capitania de São Paulo. A vila tornou-se cidade em 17 de setembro de 1818 por meio da Carta Régia de Dom João VI, com nome de Cidade de Goiás, mas a publicação oficial só aconteceu exatamente um século depois, em 17/09/1918. Foi capital do Estado até 1937, quando se efetivou a mudança da sede do governo para Goiânia” (2006: 56). Cf. FARIA, Ronaldo

Iluminuras, Porto Alegre, v. 15, n. 35, p. 126-144, jan./jul. 2014 
As pesquisas de Moraes (2012) apontam-nos os diversos aspectos da "vontade humana de Cristo", que viria, segundo a autora, caracterizada nas práticas de povoamento, dominação, exploração e urbanização do território colonial da região dos Guayazes. Com o objetivo de extrair a riqueza com a mesma intensidade que demarcou o poder espacial, estas ações explicitaram-se nas edificações dos prédios que abrigaram as instituições oficias daquela época. Um exemplo oportuno temos nas determinações reais quanto à disposição do traçado urbano da antiga Vila Boa: no referido prospecto, o legado iconográfico português do século XVIII, que embasa esta afirmação.

Analisando o prospecto, percebemos que a mesma sugere-nos diálogos com um dos quadros da artista plástica, Goiandira do Couto, datado de 1976. Há, de acordo com os olhares que lançamos sobre essas duas fontes, um discurso metalinguístico visual, concebido por meio do espaço urbano colonial, sob a perspectiva dos monumentos que refletiram e, ainda refletem a imagem simbólica do poder que existiu no passado colonial da cidade de Goiás. Resta-nos aqui, a cuidadosa tarefa de interligar as imagens às suas sensações, pois este é um importante ambiente de compreensão histórica quando nos utilizamos das visualidades como narrativas.

Portanto, as análises filosóficas de Cauquelin (2007) salientam que o entendimento sobre a imagem, a paisagem e as práticas humanas, ao instituir o interesse pela ocupação do espaço, posteriormente, sobrepuja-se nas expressões da pintura e passam a compor uma imagem tornando-a uma forma de expressão de presença ou ausência, de determinações ou escolhas, pois:

Fatores de causalidade e de significação organizando o discurso e servindo de moldura aos saberes numerosos: relevo, a flora, a fauna, os arranjos humanos, os vestígios do passado: tantas "localizações" indispensáveis às narrativas e que a elas estão ligadas. O objeto paisagem não preexiste à imagem que o constrói para um desígnio discursivo. A imagem não está voltada para as manifestações territoriais singulares, mas para o acontecimento que solicita sua presença (Cauquelin, 2007: 48-49).

As "coincidências" entre as duas imagens instiga-nos a permear as fronteiras do tempo e aventar análises acerca das permanências que reforçam a ideia de uma história oficial, na qual mantêm-se as tradições e o lugar de alguns sujeitos no domínio do poder

de. Turismo e tradição: olhares revelados pela Procissão do Fogaréu na cidade de Goiás. Dissertação apresentada ao Mestrado Profissional em Gestão do Patrimônio Cultural da Universidade Católica de Goiás - Instituto Goiano de Pré-História e Antropologia - Goiânia: 2006. 
cultural na Cidade de Goiás, atualmente. Goiandira do Couto foi membro/fundadora da Organização Vilaboense de Tradições e Artes - OVAT, fundada em 1965, instituição que detém o "controle" do que se reconhece como arte e cultura nessa cidade, indicando-nos os fios de uma trama que entrelaça entre a vida e a obra desta artista que sempre esteve imersa no cotidiano local.

Tal peculiaridade remonta à ideia de que os usos e as funções da imagem baseiam-se, historicamente, em contextos e concepções adquiridas sobre uma dada realidade. Alguns deles forjam-se baseados nos fenômenos culturais representados nas formas de agir, de pensar, ou até mesmo no reproduzir das ações sociais em temporalidades diferentes, por razões de igual modo diferentes. A perspicácia do historiador se dá na percepção desses movimentos; logo, as aproximações e os distanciamentos perceptíveis nos fenômenos históricos, semelhantemente, instigam-nos a perguntar: o tempo como sua assimetria, é capaz de gerar sincronia?

A saber, questionar a imagem e o tempo requer um exercício filosófico, subjetivo e analítico, pois "somos vetores de práticas discursivas historicamente construídas e consolidadas" (Nascimento, 2013: 249), estabelecendo, nas releituras da imagem, outras expressões da linguagem social, arquivadas nas formas e nas interpretações correlacionadas à medida que delas nos apropriamos.

Destacamos ainda que os estilos metafóricos alinham-se à narrativa histórica, da mesma forma que o tempo nos atos do fazer humano. Por isso, Cauquelin, ao se referir a estética inventiva da paisagem, aduz que: "a pintura é um intermediário interessante, porque de maneira sensível, mostra, exibe, exalta essa proeminência e anterioridade. A pintura é variação a partir do princípio" (2007: 39-40) e a narrativa histórica acrescentase a ela com palavras ampliando o sentido de compreensão nem sempre perceptível, para muitos, por meio do olhar.

Nesse sentido, vale relembrar que o historicismo linear do século XIX ignorou conceber a imagem como dispositivos para interpretar a realidade sob as variáveis do mundo social. A superação desse paradigma apresentou-nos maiores possibilidades de compreensão dos fatos histórico-culturais, pois ao se alimentar das expressões do sensível, o historiador pauta-se por interessantes pistas deixadas em tais entrecruzamentos. Vale ainda ressaltar que esta tarefa é lenta e contínua, porque os estudos da imagem trazem a peculiaridade, de acordo com Paiva (2006), de ser inconclusos, a relativos, inacabados e parciais características que adquirem por ser fruto 
da história, filha de seu tempo e da capacidade que temos de ser muitos em nós mesmos.

Para esta operação, Freitas (2004) permitirá integrar, metodologicamente, a tridimensionalidade analítica, conjugando os aspectos formais, semânticos e sociais da imagem que, cruzados ao tripé conceitual de Chartier (1990), representação, apropriação e prática, possibilite reflexões interinas sobre as origens do poder e suas permanências na cidade de Goiás, vistos por nós, no objeto em estudo, temporalidades e sujeitos distintos, porém, diametralmente, em alguns fatos, verossímeis.

\section{Ângulos Historiográficos da Paisagem}

A paisagem constitui uma forma de representação visual que mescla o real poético à utopia da verossimilhança. Considerada uma tendência artística burguesa, essa expressão pictórica teve seu auge durante o tempo histórico da "paz europeia", após um longo período de guerras e revoluções ocorridas entre meados do século XVIII à primeira metade do século XIX.

O significado historiográfico que propomos aqui, a partir de um documento administrativo, em sintonia com o quadro Largo do Rosário, da pintora regional, Goiandira do Couto, demonstra-nos que há sincronia entre as imagens, e as mesmas corroboram que "é o logos, essa razão que atravessa as coisas de lado a lado e que instaura entendimento, assegure coesão, o ajuntamento dos elementos políticos, sociais, conceituais, para que a unidade esteja presente como totalidade indivisível" (Cauquelin, 2007: 47).

Pensar duas imagens tão distantes no tempo e não distintas quanto à perspectiva e à forma desafia-nos a compressão do tangível sobre o intangível. Neste caso, referimonos ao tempo. Como conseguir aproximar duas imagens para além da posição física lateral entre elas? Enxergar semelhança apenas nas linhas formais as assemelham? Não. Essa seria uma tarefa pouco interessante. Para isso, a narrativa é o instrumento do historiador na articulação entre natureza, espaço, poder, sociedade e discurso, pois o empírico e o simbólico ganham sentidos à medida que o produto dessa fabricação discursiva visual torna-se composição daquilo que se historiciza, que define-se mais claramente, a partir da forma como nos apropriamos de algo no campo das possibilidades da representação histórica.

Iluminuras, Porto Alegre, v. 15, n. 35, p. 126-144, jan./jul. 2014 
Parafraseando Albuquerque Junior (2007), a escrita da história exige tradução de intenções, ações ou desejos guiados pela condução exímia do leme das temporalidades, de modo que risco do naufrágio pela imensidão dos anacronismos seja orientado pela consciência filosófica do espaço temporal das experiências. Portanto, ao tratarmos da pintura no tempo torna-se uma tarefa ainda mais cuidadosa, pois a consciência da realidade mesclada ao ficcional, à invocação e à evocação das subjetividades visíveis ou invisíveis numa obra de arte é argumento que precisa constar na narrativa.

Sublinhamos ainda que, ao se tratar da paisagem tais questões se complexificam, pois, "mais que um "rótulo" estético, a paisagem, confere uma unidade de visão às diversas facetas" (Cauquelin, 2007: 10) implícitas ou não naquilo que se vê. É esclarecedor dizer que o paisagismo cultural deve ser entendido dentro de uma trama de categorias e percepções fluidas capazes de possibilitar uma leitura da paisagem indissociada do sujeito que a representa ou que a modifica.

A temática das paisagens, geralmente, é dada por uma forma panorâmica em que a luminosidade é integrante do conjunto visual. O caso em estudo não foge a essa aptidão, porque na figuração da paisagem vilaboense exala-se uma fruição epistemológica e semântica comparativa, levando-nos a crer que "é o fio da narrativa, as etapas de um périplo que fazem existir os lugares sucessivos" (Cauquelin, 2007: 50). Por conseguinte, nesse conjunto de luzes, o que se pode ou se quer omitir? Esse questionamento é o viés problematizador da finalidade mediadora entre as representações iconográficas em pauta. Quando propomos uma aproximação entre elas, é possível visualizar os legados, os feitos, as práticas e o poder do colonizador, ratificados e consagrados na clarividente elipse imagético-discursiva da pintora Goiandira do Couto, no século XX.

Há ainda, a meu ver, uma declaração visual de "importância" quanto às práticas que justificaram a modificação na paisagem natural pela cultural, durante o domínio português, no auge da mineração, como forma de valorizar o espaço oficial vivido. Inclusive, no tempo presente, outros protagonistas insistem na demarcação do poder simbólico-cultural ficando, mais uma vez, no centro histórico dessa antiga cidade em evidência.

Mesmo havendo um silenciamento das memórias indígenas e africanas na localidade, a ação daquele que edificou toda essa herança arquitetônica colonial ecoa nesses "vazios". Comprovadamente, a presença do colonizador português é mais evidente começando desde a idealização do feito à sua concretização, conforme o documento português em análise, datado de 1751. Vê-se, então, que: 
(...) dos antigos códigos de posturas aos modernos projetos urbanos, com seus critérios de zoneamento, a paisagem urbana aparece como um espaço construído a partir de norma. As decisões que incidem largamente sobre a paisagem - como povoamento, a incorporação de novas técnicas ou a imposição de normas dependem da existência de um centro de poder, de hierarquias sociais eficazes, em suma, de capacidade de coerção (Silva, 1997: 213-215).

Essa relação do visível com o invisível, do natural com o cultural, da invenção à criação estabelece-se no jogo da paisagem intrínseca dessas ambiguidades. Para o historiador pensá-la, como fonte de estudo, significa capturar nos elementos formais da imagem uma composição aos resíduos culturais deixados na profundidade fugidia do artista. Durante esse exercício hermenêutico, consideramos que os significantes são mediadores de significados, e são eles os norteadores das argumentações analíticas costuradas no espaço das experiências, das vivências no passado.

A estética do paisagismo nos oferece possibilidades para estas e outras abstrações. $\mathrm{Na}$ Renascença, o lugar do homem em contato com a natureza requeria do pintor um rigoroso domínio técnico da cor, da perspectiva e do sombreamento, tidos como indicativos da mentalidade de uma época que remetia à recriação, intervenção, reinvenção e descobertas. O "Novo Mundo" orientou e inspirou alguns pintores que utilizaram do imaginário para a realização dos seus projetos artísticos durante as "grandes descobertas".

A escolha do que se colocar em primeiro ou em segundo plano partia do pressuposto dos tidos "abalos da razão", manifestos nas "ilusões visuais" que simbolizaram rupturas de paradigmas. Esses podem ser conceituados entre os desbravamentos, as conquistas e, finalmente, na superioridade eurocêntrica capturada em cenas emblemáticas pela pintura artística daquela época. Resta-nos dizer que, no afã de entender o mundo, a natureza, seus limites e a nós mesmos sucumbiram-no pela empreitada colonial, e pelo nosso estudo, destacamos a portuguesa, de acordo com o testemunho documental que subsidia o foco desta produção.

Nem mesmo o racionalismo universalista do século XVIII conseguiu dirimir o interesse das artes pela natureza. Esse gênero resiste às incursões cientificas e revolucionárias impactando-se pelas transformações que concebiam a natureza durante a renascença como acontece com qualquer prática no tempo. O século XIX apresenta com clareza estas transformações, inclusive incorporadas pela fotografia, uma expressão visual peculiar que avança pelo século XX, aliada à pintura. Essas expressões visuais do 
natural sedimentam-se no campo das artes com um status hierárquico, entre os gêneros artísticos, de forma consistente e atual.

A paisagem deve ser contemplada por meio da relação histórico-cultural ocorrida ao longo do tempo. No caso da obra de Goiandira do Couto, evidenciamos isso no rigor artesanal de sua plástica contida nos detalhes, nas cores, nas sombras, no traçado mais requintado em relação ao que pode ser visto no prospecto e, pela presença de um ícone, que discutiremos de forma mais detalhada no tópico que se segue, embora a presença da superioridade branca no espaço colonial seja indiscutível.

Fruto da transformação humana, por isso um produto cultural, a paisagem pictórica fertiliza os estudos culturais quando assumimos o desafio de propor uma historiografia crítica que relaciona teoria, conceitos e empiria. No intercâmbio entre as imagens e as palavras, suscitamos estranhamentos quanto a fundação das tradições em torno do poder e, por meio de símbolos e discursos, buscam legitimar a "goianidade", objeto desse estudo, consequentemente, tarefa do historiador. Assim sendo, recomendamos que os diálogos avancem.

\section{Linhas da Imagem, Metáforas do Tempo}

As discussões até aqui permitem-nos dizer que a interpretação histórica por traços, cores, contrastes e formas demonstra-nos um ato intricado de rigor, subjetividade apreensão de conhecimentos repletos de linguagens do mundo social. Possivelmente, o conteúdo da imagem da imagem em discussão, em meio a tais características, nos possibilitou ainda romper as generalizações ou os "erros" do anacronismo histórico da concepção linear do tempo, modo que tornou-se inteligível as pontuações conceituais sobre como os tempos históricos interpenetram-se aos sujeitos e às ações em temporalidades díspares.

Destacamos que os deslocamentos, as continuidades, as descontinuidades e a visão semântica que podemos lançar sobre esses movimentos temporais contribuem, incialmente, para entender os diálogos icnográficos propostos e podem, de certo modo, mesmo distantes no tempo, reverberar no desaparecimento da distância temporal. Religada por meio da ideia de que o tempo histórico fundamenta-se teoricamente em bases calcadas na experiência, Koselleck (2006) coloca em evidência uma reflexão filosófica do tempo histórico no qual o passado é um espaço de experiências, direcionando horizontes de expectativas para o presente/futuro. 
Portanto, a intenção de Goiandira do Couto, ao pintar a tela Largo do Rosário, em 1976, lança um olhar para este espaço de experiências, materializado no legado da paisagem urbana desta cidade de estilo colonial. A releitura da imagem do já mencionado prospecto português em comparação com a tela da artista plástica goiana é um instrumento que direciona possibilidades entre as intersecções no nível de "justaposições” e interdependências dos exemplos imagéticos e conceituais aludidos que fertilizam os aspectos historiográficos, mas não nos oferecem respostas imediatas.

Portanto, a necessidade de discussões teóricas, como por exemplo a justaposição temporal, permite-nos romper as barreiras que levariam a uma narrativa inócua, ou seja, próxima da exatidão.

\begin{abstract}
O estudo da semântica histórica mostra que todo conceito que faz parte de uma narrativa ou de uma representação (...) torna inteligíveis contextos, precisamente por não reduzi-los à sua singularidade histórica. Os conceitos não nos instruem apenas sobre unicidade de significados (sob nossa perspectiva) anteriores, mas também contém possibilidades estruturais; colocam em questão traços contemporâneos no que é não contemporâneo e não pode reduzir-se a uma pura série histórica temporal (Koselleck, 2006: 142).
\end{abstract}

Trazer à baila as implicações teóricas sobre o conceito de tempo ajuda-nos a tangenciar os dois legados artísticos em suas diferentes temporalidades e mesmo assim encontrarmos meio de sobreposição discursiva e analítica "amalgamadas com este mundo, pleno de curiosidades, trilhas, desejos e rumos, em um processo fluído, descontínuo e, portanto, dinâmico e desafiador" (Tourinho e Martins, 2013: 61). Por esta direção, temos na reflexividade temporal o fio condutor que o jogo entre essas imagens desencadeia à medida que as confrontamos.

Nesse sentido, percebe-se que uma primeira narrativa histórica visual surge com o prospecto e perpetua-se na obra de Goiandira do Couto. Ao "reproduzir" o traçado urbano, determinado pelo colonizador, reforça os espaços de poder herdados dos tempos coloniais. Não que esta não possa ser uma opção do artista, porém há uma particularidade nas expressões pictóricas da pintora, no momento em que tais discursos se repetem noutros espaços de poder desta cidade, dando-nos sentido de uma informação visual baseada na fabricação de uma realidade.

A nosso ver, esta opção ofusca outros espaços que demonstrariam outros sujeitos, outras práticas integradas, aparentemente ou não a este jogo de poder, precipuamente. Assim, o valor epistemológico desse estudo ora sobressai, pois um paradigma 
dominante tornou-se o foco de investigação e, consequentemente, de releituras que problematizam as narrativas visuais em estudo.

Antes das comparações entre as imagens, o contexto, especialmente do prospecto, deve ser melhor explanado. As análises de Moraes (2012) direcionam a um entendimento das razões de tal registro iconográfico, pois aventou-se, sob a ótica do povoamento e da urbanização, ocorrida no interior do Brasil no século XVIII, uma forma clara de manifestação do poder europeu sobre o espaço "descoberto", rico em ouro e em possibilidades da expansão dos domínios geográficos oportunos aos interesses portugueses por meio da ruptura do Tratado de Tordesilhas.

A união dos interesses políticos/administrativos com os de cunho religioso sedimenta condições para investimento na arquitetura urbana, pois o rápido e crescente desenvolvimento do arraial o leva, em poucos anos, à categoria de vila. Porém, outros valores deveriam ser impressos à identidade da população local para que o possível arrefecimento aurífero não lavasse ao esvaziamento populacional de forma súbita. O investimento da Coroa na implementação urbana local, das estruturas que abrigariam as representatividades do poder real incorporadas aos investimentos materiais e simbólicos objetivava e justificaria que a permanecia do poder não seria apenas durante a exploração do ouro. Por isso, a junção entre o poder real e o poder eclesiástico baseara o cerne da política expansionista portuguesa no século XVIII, em Goiás.

Daí, a importância das irmandades religiosas para sedimentares vínculos sociais, modos, costumes religiosos que norteariam elos de cultura com o lugar, conforme afirma a tese de Moraes (2012).

(...) empreender amplo programa de reforma e ampliação dos logradouros e prédios públicos. Entre outros projetos, empreendeu a reconstrução de pontes, a edificação do matadouro, a implantação do passeio público e a reordenação da expansão urbana. Ao que parece, pretendia com os melhoramentos projetados assegurar fixação dos moradores da vila e atrair outros, que para ela convergiam em busca de todos os bens da vida segura e conversável. Assim, estariam assegurados alguns dos objetivos primeiros da fundação de Vila Boa: a vigência sobre o território que fora espanhol e, em nome de $E l$ Rei, administração da justiça e a garantia da segurança da capitania (Moraes, 2012: 40).

Enxergamos que, além do ouro, a fixação de pessoas rendia à Coroa os lucros simbólicos - referimo-nos ao domínio geográfico que culmina no poder efetivo. Já os lucros reais vinham atender aos ganhos materiais baseados na lucratividade quando a Coroa valia-se "de vários expedientes para arrecadar impostos devidos, tanto pela mineração e pela pecuária, quanto pelas atividades manufatureiras” (Moraes, 2012: 41) 
praticadas pela variedade populacional existente, da qual o ouro era a base, porém, não a totalidade dos saberes e fazeres na vida urbana de Vila Boa naquela época.

Por isso, incentivar a vida urbana, oferecer condições de fixação populacional, definir a ocupação do espaço, conforme nos apresenta o prospecto abaixo, eram uma racional ação portuguesa para que o poder fosse demarcado por instrumentos antagônicos a uma circunstância temporária.

O tom pastel avermelhado, os traços geométricos ressaltando os telhados em tom vermelho mais escuro, o zigue-zague das ruas e suas edificações domiciliares compondo-se aos prédios públicos e eclesiásticos, o traçado urbano mesclam-se a uma rala vegetação onde o Rio Vermelho é suprimido. Nem mesmo o esboço de uma ponte é vista. Isso demonstra o que já mencionamos: a paisagem é parte do real e não o retrato fidedigno do mesmo.

A inscrição acima da gravura media o ângulo da imagem quanto à disposição geográfica da cidade. Nela diz: Prospecto de Vila Boa tomada da parte do norte para o sul anno de 1751. Vemos num primeiro plano a rua do comércio marcada pela caraterística da existência de um maior número de portas do que janelas. Ao centro temos os prédios eclesiásticos marcados à direita pela matriz e à sua lateral o consistório da Irmandade do Senhor dos Passos e Santíssimo Sacramento ${ }^{4}$. Em último plano, no atual largo do Chafariz, aparecem a capela da Boa Morte e antiga Casa de Câmara e Cadeia, atual Museu das Bandeiras ${ }^{5}$. Pouco se alterou a paisagem urbana pensada pelo colonizador, embora o que inseriu-se a urbe real merece considerações das quais trataremos em seguida.

\footnotetext{
${ }^{4}$ Cf. MORAES, Cristina de Cássia Pereira. Do corpo místico de Cristo: irmandades e confrarias na Capitania de Goiás (1736-1808). Goiânia: FUNAPE, 2012.

5 “Criado em 1949, o Museu das Bandeiras (Muban) tem a missão de preservar, pesquisar e comunicar a memória nacional relativa à ocupação bandeirante na região Centro-Oeste do Brasil. O museu ocupa a antiga Casa de Câmara e Cadeia da Província de Goyaz. Ao longo de sua história, a Casa passou por uma série de intervenções físicas". Cf. http://www.museus.gov.br/muban-comemora-61-anos-com-debates-eexposicoes/
} 


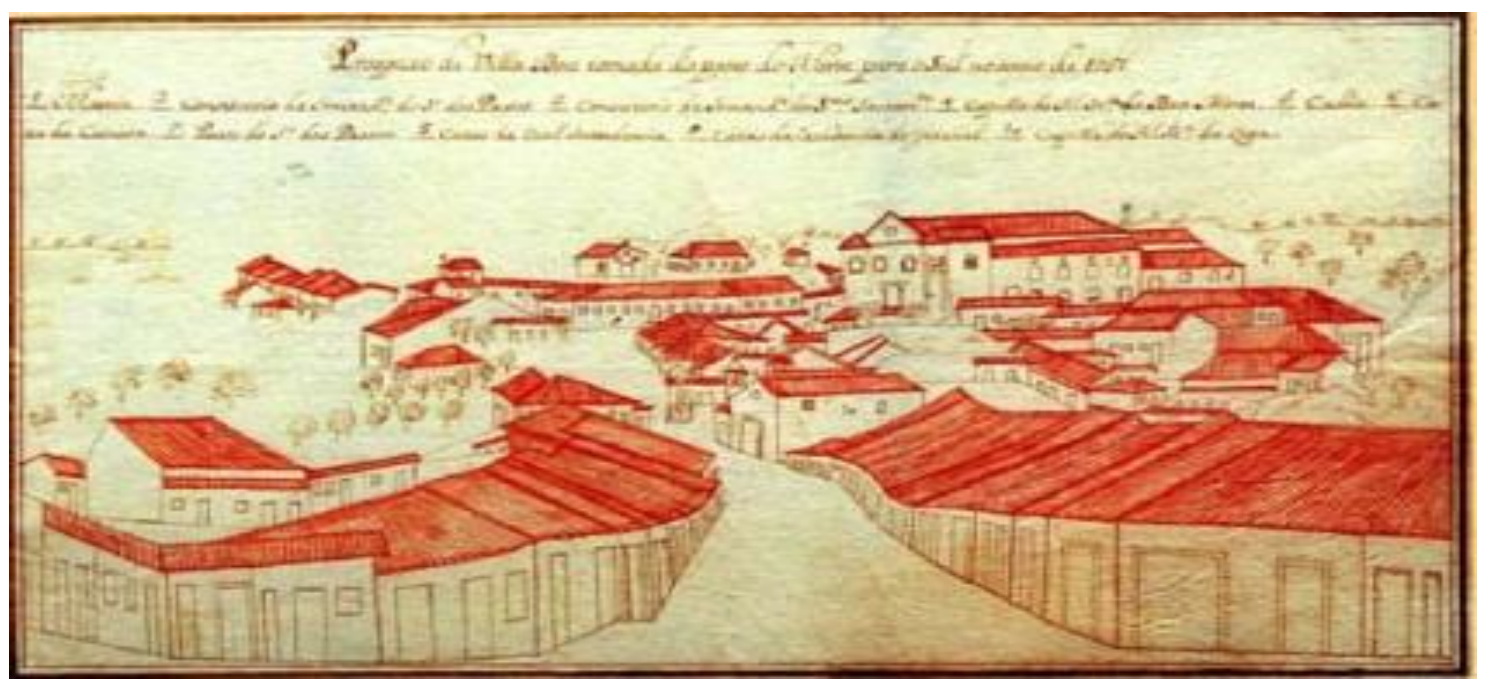

Figura 1: Prospecto de Vila Boa - Vista no sentido inverso, isto é, do norte para o sul, em 1751 (original da Casa da Ínsua, Portugal). IN: MORAES, Cristina de Cássia Pereira. "Do corpo místico de Cristo: irmandades e confrarias na capitania de Goiás (1736 a 1808)”, 2012: 48.

A rigor, para esta reflexão, inserimos a obra de Goiandira do Couto, a fim de estabelecer diálogo iconográfico com direções hermenêuticas. Ao entrecruzar as imagens, enxergamos similaridades formais e, cabe a nós, os dizeres semânticas que suscitam algumas implicações sociais, ora envoltas na realidade da cidade de Goiás, onde enxergamos que os tempos coloniais ressignificam-se na atualidade, por meio de outros agentes que, de forma intencional ou não, perpetuam, em certa medida, tais relações de poder no campo simbólico da cultura.

Sobre estas implicações se faz necessário apontar alguns itinerários da pintora que "respondem", ou melhor, situam algumas das abstrações aqui expostas e que direcionam as tensões que historicizam esta abordagem.

Nos anos de 1965 surge, na cidade de Goiás, a OVAT - Organização Vilaboense de Artes e Tradições. Integrada ao grupo fundador ${ }^{6}$, Goiandira do Couto passa, além de ícone cultural local, a representar os membros tidos como "guardiões" da cultura, a fim de reconstruir tradições ou inventá-las com o propósito de, segundo ela, em depoimento oral a pesquisadora Mônica Martins da Silva, "naquela época, eles queriam atrair pessoas porque os turistas eram apenas 'uns gatos pingados"” (Silva, 2008: 63).

\footnotetext{
6 "São os fundadores da OVAT: Goiandira Aires do Couto (brasileira, solteira, professora), Joiza Pereira Oliveira (brasileira, casada, professora), Joice Periera Oliveira (brasileira, solteira, professora), Elina Maria da Silva (brasileira, casada, professora), Elder Camargo de Passos (brasileiro, casado, advogado), Humberto do Nascimento Andrade (brasileiro, casado, comerciante), Antônio Carlos Bastos Costa Campos (brasileiro, casado advogado), Neuza Velasco (brasileira, casada, professora), Erlande da Costa Campos (brasileiro, casado, bancário), Hecival Alves de Castro (brasileiro, casado advogado) (2006: 56)". Cf. FARIA, Ronaldo de. Turismo e tradição: olhares revelados pela Procissão do Fogaréu na
} 
Mas, por que eles? Por qual motivo a artista não se inclui, nesta entrevista, entre o grupo? Ora, o papel de Goiandira é claro entre os membros da OVAT, pois coube a ela a tarefa de "criar" as alegorias do mais notável legado desse grupo para as tradições inventadas na cidade de Goiás: a Procissão do Fogaréu.

Ela afirma que eles que criaram tudo a partir de várias pesquisas em livros. A primeira Procissão do Fogaréu, segundo ela, foi realizada em 1967, data que coincide com a que registra os seus desenhos de criação do figurino da festa. Embora a construção do ritual esteja mais relacionada à sua iniciativa pessoal, o depoimento é interessante porque dessacraliza a criação do evento e estabelece outros elementos que interessam na percepção da criação (Silva, 2008: 63).

A contradição no discurso parece se dar quando a intenção de criar a OVAT, em 1965, parte de uns e, ao propor-lhe a ideia de integrar-se ao mesmo, diante de suas habilidades artísticas, a criação do formato da festa, inserida no catolicismo popular, a torna detentora da patente daquilo que chamaremos da materialização de sua arte no real "sagrado". A assinatura de Goiandira do Couto nos desenhos que definem a estética dos farricocos, dos guardas romanos, da Verônica, das carpideiras e outros personagens, a cadência entre os "guardiões" e inventores das tradições locais resistem ao tempo e, ainda hoje, incorporam-se ao patrimônio imaterial, que de forma aleatória, ou não, foi algo que esses “jovens”, dos anos de 1960, pensaram tendo nessa época os primeiros movimentos patrimoniais consolidados apenas no campo material.

Nos documentos do arquivo da Fundação Frei Simão Dorvi - FFSD - localizado na cidade de Goiás, encontramos outras evidências que apontam a participação da protagonista nas atividades culturais, religiosas ou peculiares da cidade de Goiás. No documento encontrado, lemos um dado que nos direciona a uma análise mais verossímil da obra pictórica Largo do Rosário, de 1976, em comparação com o prospecto de 1751.

\begin{abstract}
A 5 de agosto de 1934 por Mons. Rdo. Pe. Abel Camelo, representado S. Excia. Dom Emanuel Gomes de Oliveira, Arcebispo de Goyas, foi lançada a pedra fundamental do novo Santuário, em homenagem Nossa Senhora do Rosário, após a missa conventual das 8 hs... Achavam-se presentes o Rdo. Pe. Superior dos Dominicanos, o Rdo. Frei Germano Lhech, o Rdo. Frei Bernardo Gandim, Rdo. Frei Gonzalvo Carneiro Leão, irmão Alvaro Criado, autoridades civis, muitas pessoas gradas e boa massa popular. A contento de todos foram iniciados os trabalhos que a excelsia Virgem do Rosário esparamol-o há de proteger para que em breve erga-se seu novo e majestoso santuário. Antes de iniciar-se a demolição do antigo Santuário de Nossa Senhora do Rosário nos dias 3,4 e 5 de maio solenizou-se o segundo
\end{abstract}

cidade de Goiás. Dissertação apresentada ao Mestrado Profissional em Gestão do Patrimônio Cultural da Universidade Católica de Goiás - Instituto Goiano de Pré-História e Antropologia -Goiânia: 2006. 
centenário da Igreja do Rosário. Revestiu-se do maior brilhantismo e respeito a festa do dia 05. Às autoridades religiosas, civis, forenses e militares uniu-se a população de Goyaz em peso, enchendo o largo fronteiro à nova Igreja. Em frente à fachada engalanada do novo Templo os diversos Oradores Dr. Joaquim Ferreira dos Santos, ar. Antonio Jurema de Guimaraes, srt. Goiandira do Couto e Dr. Joaquim Jubé Junior enalteceram o ideal das energias espirituais imorredouras que concretizam o culto da Virgem e o Catholicismo, ideal do qual as Egrejas multisseculares simbolizam a perenidade vencedoura (LIVRO DE TOMBO DAS IGREJAS, 1966: 40$, v. $)^{7}$.

Nessa discussão, o destaque se dá sobre o lugar cultural de Goiandira do Couto, pois no documento citado, sua presença na destruição da antiga igreja em louvor à Nossa Senhora do Rosário dos Pretos, datada do século XVIII, local onde existiu uma das mais antigas irmandades dos tempos coloniais, diz muito sobre suas escolhas e como era sua colocação na sociedade vilaboense dos anos de 1930. A antiga construção, de estilo colonial, foi demolida no século XX, dando lugar a uma suntuosa arquitetura de estilo neogótico. Faz-se necessário estabelecer um círculo hermenêutico para ler e analisar a obra de Goiandira do Couto, justificaria instar a permanência dessa "originalidade" colonial vivida pela cidade de Goiás no século XVIII.

Estamos diante de uma assinatura pictórica que preza os sombreamentos, e o uso de cores quentes, o dourado das várias colorações da areia retirada da Serra Dourada dão o aspecto de luminosidade parcial do entardecer. Chama-nos a atenção a dimensão física da tela que é considerável diante da técnica artesanal utilizada pela artista. O jogo de luz e sombras percorre a obra e também os ângulos da paisagem escolhida para representar.

Há, na pintura de Goiandira do Couto, duas alterações geradas pelo tempo, comparada à paisagem dantes idealizada pelo colonizador. Percebe-se a presença de um busto $^{8}$ e de um cruzeiro.

Sobre esse último, os estudos de Quadros (2005) discutem que nas primeiras décadas do o século XX, Luís do Couto, pai de Goiandira do Couto, dentre outros membros da elite local, decide, por colocar tal ícone, enaltecedor da memória branca, como marco da chegada dos bandeirantes naquela região. $O$ que nos causa estranhamento repousa na seguinte questão:

\footnotetext{
${ }^{7}$ FFSD- Fundação Frei Simão Dorvi - Revista Trimestral de História e Geografia, TOMO XII, com 67 páginas datilografadas em espaço 2. Goiás, 09 de maio de 1966.

${ }^{8}$ Cf. BARBOSA, Raquel Miranda. Muito além das telas douradas: narrativas pictóricas em Goiandira do Couto. Anais do XXVI Simpósio Nacional de História - ANPUH. São Paulo: jul. 2011: 07.
} 
Ainda em 1918, quando eram comemorados os cem anos da elevação de Goiás à categoria de cidade, a chamada "Cruz do Anhanguera" fora encontrada. Estranhamente, isso ocorreu bem longe daquela área, nas proximidades de Catalão. Os operários que construíam a estrada ferro encontraram o referido objeto. A elite de Goiás, todavia, resolveu requisitá-la pela possibilidade de remontar ao passado dos bandeirantes. A famosa cruz não deixa de ilustrar o desapego com o passado predominante nesse período. Um pequeno pedestal para coloca-la foi construído próximo às margens do Rio Vermelho e houve missa campal para inaugurá-la (Quadros, 2005: 03).

Catalão, município localizado na região sudeste do estado de Goiás, é a cidade natal da família de Luís do Couto. A chegada à cidade de Goiás, na segunda década do século XX e Goiandira do Couto, apesar disso, possuía tenra idade na época, embora tenha sido testemunha ocular de muitos fatos desencadeados pelo pai onde passaram a residir. Conforme comentamos, a citação acima, informa-nos claramente, o teor das suas influências culturais e a sua posição de testemunha ocular dos discursos oficias que sustentam a maioria das tradições inventadas na Cidade de Goiás, especialmente nos anos de 1960, ratificadas em seu discurso pictórico a partir desta mesma data.

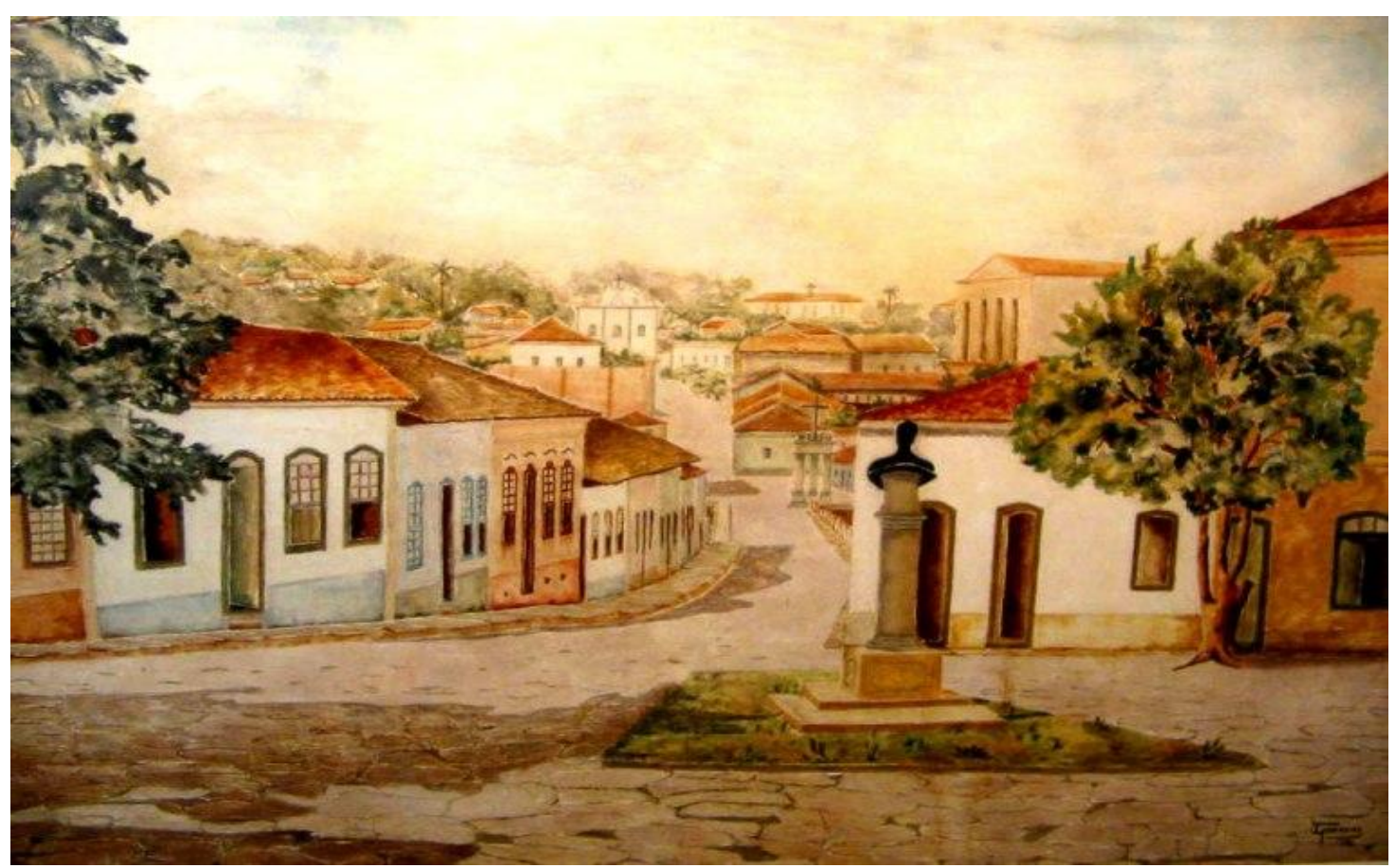

Figura 2: Goiandira do Couto, Largo do Rosário $(141$ x $93 \mathrm{~cm})$ - Vista da cidade, 1976. In: FERREIRA, Taís Helena Machado. "Faz uma casa com areia": a cidade de Goiás e as areias coloridas na trajetória de Goiandira Ayres do Couto (p.179). Dissertação (mestrado) UFRJ/EBA, Programa de Pós-Graduação em Artes Visuais, 2011.

É quase indubitável afirmar que a visão de mundo narrada em sua pintura sofre uma tendência da impregnação dos tempos vividos, das histórias relatadas, das 
articulações descontínuas remanescentes em determinados lugares ou retraçadas em seus discursos visuais. Em cima disso, licenciamo-nos de Cauquelin para ratificar que nos “jogos de paisagem, jogos com o tempo, jogos com a linguagem" (2005: 111) encontraremos uma possível circularidade à ressignificação do poder na cidade de Goiás, ponto fulcral para o avanço do campo teórico desse objeto de estudo.

Sobre o documento transcrito acima, problematizamos o lugar social e cultural da pintora, especialmente após a criação da OVAT, pois explicitam-se indícios do porquê de algumas permanências em sua obra pictórica. Que imagem se quer "vender" sobre a cidade de Goiás? As intencionalidades imagéticas se alinham às "escolhas" quanto ao discurso e ideia dos "inventores" da cultura, das artes e das tradições vilaboenses no auge dos anos de 1960? Qual o objetivo de se construir, naquela época, a ideia de guardião da cultura? Estes questionamentos impulsionam esta pesquisa e fertilizam as continuidades sobre o tema cultura, arte e poder na cidade de Goiás.

Diante desse breve exposto de inquietudes, é certo afirmar que uma obra de arte emite discursos no/do tempo que encadeiam-se na perspectiva "de cada fórmula de representação, e também consonante os distanciamentos dos saberes e das competências dos diferentes públicos colocados em posição de ver o poder através dos seus signos" (Chartier, 1990: 221). Portando, o lugar social e cultural adquirido por Goiandira do Couto lhe conferiu integrar-se por si mesma e, posteriormente, pela legitimação dada na oficialização do seu papel de guardiã de tradições, via OVAT, nos anos de 1965, condições que a levou a convalidar a reconstrução iconográfica desse passado visto sob um aspecto, pois o que se representa é fruto do que se viveu refletido na compreensão ontológica da experiência, afirma Gadamer (1997).

A orientação do pensador nutre metáforas, secciona as linhas, altera o curso do tempo, reflete muitas imagens e, numa delas, o historiador percebe que é passível e possível redefini-la por meio da compressão que o conhecimento histórico produz. Isso representa um pouco da alteridade que sentimos pelo passado. 


\section{Algumas Considerações Finais}

Sou livre para o silêncio das formas e das cores. Manoel de Barros

Discutimos, neste escopo, breves análises sobre os aspectos históricos e historicizantes quanto ao entendimento semântico e social emanados na obra pictórica de Goiandira do Couto. Sob o ponto de vista formal, as obras da pintora em estudo não nos apresentam complexidade acadêmica, embora o apelo artesanal de suas obras numa busca incessante pela perfeição dos traços e da reprodução fidedigna de uma cidade, de suas memórias, seja bastante peculiar.

Essa tendência artística, concebida na segunda fase de sua trajetória artística, utilizando-se da técnica em areia sobre fibra de madeira e cola à base d`água, surge em fins dos anos de 1960, quando um boom cultural da cidade de Goiás ganhava outro contorno com a fundação da OVAT - Organização Vilaboense de Artes e Tradições. Reforçou-se, com essa instituição cultural, um lugar de poder que Goiandira do Couto, entre os guardiões e inventores das tradições locais, baseadas num discurso elitista legitimado pelo poder simbólico que a maioria dos pertencentes a este grupo, possuía na cidade de Goiás de então.

Ao propormos uma exposição sobre arte e paisagem, evidenciamos que muito há para se pensar e problematizar sobre esse estilo pictórico no qual as cadências sugerem oportunas comparações, sincronias, diacronias objetivadas pela busca do sentido, especialmente aqueles ligados aos conhecimentos sobre a arte, a cultura e o poder na cidade de Goiás. Abrimos essa janela e vislumbramos, com este estudo, a fertilidade nos horizontes fluidos para outras problematizações acerca desse tema, pois a fissura científica amplia-se a cada olhar que lançamos sobre a paisagem empírica e teórica dessa temática.

A comparação entre as imagens sugeridas neste artigo teve como intuito provocar reflexões que ainda nos motivam a percorrer um caminho hermenêutico de compreensão do que se é discursado por Goiandira do Couto ao pintar a cidade de Goiás, já que esta pintora se torna referência quando se trata dos valores "culturais da terra", não desconsiderando todo um arcabouço social que envolve esta mulher de elite. Percebemos isso quando encontramos, no documento citado, a ênfase dada ao seu 
nome, única mulher notabilizada entre as autoridades masculinas, num "evento" religioso de demolição de uma construção colonial, dedicada a uma santidade de devoção dos negros, onde existiu uma irmandade dos negros, no século XVIII, conforme as afirmações de Moraes (2012).

Muitos são os silêncios e os vazios historiográficos sobre a história, a cultura, as artes e o poder na cidade de Goiás, na segunda metade do século XX. Nesse sentido, as obra de Goiandira do Couto e suas vivências entre os grupos de poder político, social, simbólico e cultural nessa localidade, desde sua vinda da cidade de Goiandira-Go, ainda bem pequena, para a cidade de Goiás, em princípios do século $\mathrm{XX}$, justificam aos poucos suas intencionalidades ou não ao exprimir uma cidade, seus espaços de poder e sua inalterabilidade que vai, ao olhar do historiador, Muito além das Telas Dourada. ${ }^{9}$

\section{Referências}

ALBUQUERQUE JUNIOR, Durval Muniz de. História: a arte de inventar o passado. Bauru, SP: EDUSC, 2007.

CAUQUELIN, Anne. A Invenção da Paisagem. (Coleção todas as Artes), São Paulo: Martins Fontes, 2007.

CHARTIER, Roger. História Cultural entre práticas e representações. Rio de Janeiro: Bertrand, 1990.

FARIA, Ronaldo de. Turismo e tradição: olhares revelados pela Procissão do Fogaréu na cidade de Goiás. Dissertação apresentada ao Mestrado Profissional em Gestão do Patrimônio Cultural da Universidade Católica de Goiás - Instituto Goiano de Pré-História e Antropologia Goiânia: 2006.

FREITAS, Arthur. História e Imagem Artística: por uma abordagem tríplice. Revista Estudos Históricos, Rio de Janeiro n. 34, julho-dezembro de 2004: 3-21.

GADAMER, Hans- George. Verdade e Método. Trad. Flávio Paulo Meuer. Petrópolis- RJ: Vozes, 1997.

KOSELLECK, Reinhart. Futuro Passado. Contribuição à semântica dos tempos históricos. Rio de Janeiro: Contraponto, Editora Puc-RJ, 2006

MENEZES, Ulpiano T. Bezerra de. Fontes Visuais, Cultura Visual: balanço provisório, propostas cautelares. Revista Brasileira de História. São Paulo: v. 23, n45, 2003: 11-36.

MORAES, Cristina de Cássia Pereira. Do corpo místico de Cristo: irmandades e confrarias na Capitania de Goiás (1736-1808). Goiânia: FUNAPE, 2012.

\footnotetext{
${ }^{9}$ Título de artigo introdutório a essa temática. Foi apresentado e publicado nos Anais do XXVI Simpósio Nacional de História - ANPUH • São Paulo, julho 2011
}

Iluminuras, Porto Alegre, v. 15, n. 35, p. 126-144, jan./jul. 2014 
NASCIMENTO, Erinaldo Alves do. A pesquisa em artes e as perspectiva da cultura visual. In: MARTINS, Raimundo; TOURINHO, Irene (orgs). Processos \& Práticas de Pesquisa em Cultura Visual e Educação. Santa Maria: Editora UFSM, 2013.

PAIVA, Eduardo França. História \& Imagens. 2 ed. 1 Reimpressão. Belo Horizonte: Autentica, 2006.

PESAVENTO, Sandra Jathay. História e História Cultural. 2 ed. 1. Reimpressão. Belo Horizonte: Autêntica, 2005.

QUADROS, Eduardo Gusmão. Quando Anhanguera chegou em Goiânia: a transferência da memória na mudança da capital. Texto inédito, fruto do projeto de pesquisa para a Universidade Estadual de Goiás - UnU de Goiás: Bandeirantismo, Memória e Historiografia. Cidade de Goiás: 2005.

SILVA, Mônica Martins. A "Invenção do Fogaréu" e enredos do folclore vilaboense. In: BRITTO, Clóvis Carvalho (Org). Luzes e Trevas: Estudos sobre a Procissão do Fogaréu na cidade de Goiás. Rio de Janeiro: Corifeu, 2008.

SILVA, Francisco Carlos Teixeira da Silva. História das Paisagens. In: CARDOSO, Ciro Flamarion; VAINFAS, Ronaldo (Orgs.). Domínios da História: ensaios de teoria e metodologia. Rio de Janeiro: Campus, 1997: 203.

TOURINHO, Irene; MARTINS, Raimundo. Reflexividade e pesquisa empírica nos infiltráveis caminhos da cultura visual. In: TOURINHO, Irene; MARTINS, Raimundo (orgs). Processos \& Práticas de Pesquisa em Cultura Visual e Educação. Santa Maria: Editora UFSM, 2013. 